\title{
O Bem Viver, Educação Ambiental e Crise Pandêmica: entrelaçamentos crítico-transformadores
}

\section{Good Living, Environmental Education and Pandemic Crisis: critical-transforming Entanglements}

\author{
Vivir Bien, Educación Ambiental y Crisis Pandémica: \\ entrelazamientos crítico-transformadores
}

Lucas Antônio Viana Botêlho ${ }^{1}$

\begin{abstract}
Resumo
Este artigo tem o objetivo de compreender as relações entre a Educação Ambiental e o Bem Viver, enquanto perspectiva crítico-transformadora, dentro do cenário de crise pandêmica atual e noutros cenários, apostando em outras ideias e esperanças pedagógicas. Para tanto, são levantados elementos reflexivos, pautados numa revisão bibliográfica que não tem como intuito esgotar as temáticas que se entrelaçam e fundamentam a discussão, mas iluminar as ideias e promover diálogos que possam convergir para proposições entre o Bem Viver e a Educação Ambiental. A crise pandêmica (2020-2021) promove debates sobre práticas pedagógicas, em virtude do isolamento social e fechamento dos espaços escolares, migrando a modelos virtuais. Nisto, a Educação Ambiental precisa ampliar seu alcance, evidenciando a necessidade de um pensar-agir crítico-transformador a partir do Bem Viver, estimulando com o romper de práticas encartilhadas para mudar a sociedade-mundo com outros olhares e práticas.
\end{abstract}

Palavras-chave: Educação Ambiental. Bem viver. Crise Pandêmica. Ensino-aprendizagem.

\begin{abstract}
This article aims to understand the relationship between Environmental Education and Good Living, as a criticaltransformative perspective, within the current pandemic crisis scenario and in other scenarios, betting on other pedagogical ideas and hopes. To this end, reflective elements are raised, based on a bibliographic review that does not aim to exhaust the themes that intertwine and justify the discussion, but to illuminate ideas and promote dialogues that may converge to propositions between Bem Viver and Environmental Education. The pandemic crisis (2020-2021) promotes debates on pedagogical practices, due to social isolation and closure of school spaces, migrating to virtual models. In this, Environmental Education needs to expand its reach, highlighting the need for critical-transformative thinking-acting based on Well Living, stimulating with the breaking of bound practices to change the world-society with other views and practices.
\end{abstract}

Keywords: Environmental education. Good living. Pandemic Crisis. Teaching-learning.

\section{Resumen}

Este artículo pretende comprender las relaciones entre la Educación Ambiental y el Buen Vivir, en tanto que perspectiva crítico-transformadora, dentro del actual escenario de crisis pandémica y otros escenarios, apostando por otras ideas y esperanzas pedagógicas. Para ello, se plantean elementos de reflexión, a partir de una revisión bibliográfica que no pretende agotar los temas que se entrecruzan y fundamentan la discusión, sino iluminar las ideas y promover diálogos que puedan converger a proposiciones entre el Buen Vivir y la Educación Ambiental. La crisis pandémica (2020-2021) promueve debates sobre las prácticas pedagógicas, debido al aislamiento social y al cierre de los espacios escolares, migrando a modelos virtuales. En esto, la Educación Ambiental necesita ampliar su alcance, destacando la necesidad de un pensamiento-acto crítico-transformador desde el Buen Vivir, estimulando con la ruptura de prácticas compartidas para cambiar la sociedad-mundo con otras miradas y prácticas.

\footnotetext{
${ }^{1}$ Doutor em Geografia pela Universidade Federal de Pernambuco (PPGEO/UFPE), Professor formador II no curso de Licenciatura em Geografia (DCG/UFPE/UAB. E-mail: lucasviana.botelho@gmail.com
} 
Palabras clave: Educación ambiental. La buena vida. Crisis pandémica. Enseñanza-aprendizaje.

\section{Introdução}

Ao longo dos últimos meses, desde janeiro de 2020, a sociedade-mundo teve de readaptar-se para enfrentar um dos males mais assustadores e inesperados destas primeiras décadas do século XXI: a pandemia do novo coronavírus (SARS-CoV-2), provocador da COVID-19. Se, por um lado, já era esperado que fossemos assolados por doenças provocadoras de cenários como este, num passado recente, por outro, pouco nos preparamos para lidar com tais situações, sobretudo pela ausência de equilíbrio na relação estabelecida entre homem e natureza.

Como consequência do agravamento da ausência de maneiras como a sociedade global atua para mitigar ou sanar os efeitos nocivos da chamada crise socioambiental (ACOSTA, 2016), ou socioecológica (LEFF, 2009), a crise pandêmica atual apresenta-se como um dos retratos asseverados e que alardeiam para a necessidade de uma consciência humanitária global, frente aos iminentes riscos do porvir. Neste período histórico, no qual o homem se centra como sujeito fundamental na Terra - o antropoceno (SOFFIATI, 2008) - o colapso social, político, econômico e ambiental tem provocado grande perda de qualidade de vida, ao passo em que há aumento de riscos significativos ao bem-estar global. Isto revela um cenário a se agravar ainda mais, caso permaneçamos mantendo o desenvolvimento pautado no neoliberalismo capitalista como roldana que impulsiona o modo de vida que temos hoje.

Imersos neste contexto, vê-se necessário buscar alternativas permeadas por ideias e práticas crítico-transformadoras, que reinventem a existência do homem na Terra e sua relação com a natureza e consigo mesmo, de forma que seja possível combater o avanço desenfreado da crise em expansão. A ideia do Bem Viver, definida e defendida por Alberto Acosta (2016), soa como uma esperança e uma saída cautelosamente exposta para todo esse cenário catastrófico, porém, como sinaliza Santos (2007), trata-se de uma utopia crítica, entre tantas, contudo com potencial para reinventar a existência do homem em sua Terra-pátria e a produção de outro modelo societário, que vise a reinserção da natureza não apenas como coadjuvante, como estrado para o progresso técnico-científico e existencial humano, mas como fundamental para a permanência da vida na/da Terra, reconhecendo esta como parte do que somos.

$\mathrm{O}$ Bem Viver insurge-se ao antropocentrismo e reconhece as diferentes formas de vida como também partícipes da Terra e como iguais vidas necessárias para sua manutenção. Desse modo, mirando o desenvolvimento dessa razão sensível, como afirmado por Fraga (2016), a Educação Ambiental contribui, fundamentalmente, para a propagação das ideias que podem libertar os sujeitos sociais dos imaginários e práticas capitalistas, ao passo em que reconhecem o mundo como palco de sua existência, protagonismo e resistência humana para enfrentamento não apenas da crise pandêmica atual, mas de futuras crises cíclicas que compõem o sistemamundo capitalista vigente.

As argumentações aqui contidas têm o objetivo de compreender as relações entre a Educação Ambiental e o Bem Viver, enquanto perspectiva crítico-transformadora, dentro do cenário de crise pandêmica atual e noutros cenários, apostando em outras ideias e esperanças pedagógicas. Para tanto, são levantados elementos reflexivos, pautados numa revisão bibliográfica que não tem como intuito esgotar as temáticas que se entrelaçam e fundamentam a discussão, mas iluminar as ideias e promover diálogos que possam convergir para proposições entre o Bem Viver e a Educação Ambiental, de modo a municiar os sujeitos escolares de ideias crítico-transformadoras para enfrentamento da crise pandêmica atual e da crise socioambiental global.

Nesse sentido, intenta-se argumentar acerca das possibilidades e potencialidades críticotransformadoras entre o Bem Viver e a Educação Ambiental, tendo como pano de fundo a 
sociedade-mundo em crise e as práticas pedagógicas dentre desse contexto. Tais elementos reflexivos estão ancorados em autores que têm contribuído amplamente para o debate tanto acerca do Bem Viver, como Acosta (2016), mais centralmente, Alcântara e Sampaio (2017), Sezyshta (2018), entre outros, quanto da Educação Ambiental, como Jacobi (2015), Reigota (2010), Soffiati (2008), Lobino (2013) e outros.

Crê-se que a articulação entre esses dois eixos, não somente neste texto, mas em outras circunstâncias e veículos, funcionam como esperança para dias que virão, nos quais teremos de reaprender a existência humana não mais como nociva à Terra, sobretudo em virtude da necessidade de readaptarmos as práticas sociais e ambientais para lidarmos com futuras crises que poderão ocorrer. A Educação Ambiental tem muito a contribuir para a formação socioambiental dos sujeitos sociais escolares, e o Bem Viver atua como ideia críticotransformadora que não apenas ressignifica a EA do tempo presente e futuro, mirando uma ecoconvivência, mas também abre janelas para mudar a maneira como enxergamos o mundo em que vivemos, como lidamos com a crise socioambiental, desde os espaços mais aproximados até as escalas mais amplas, buscando reconfigurar o modelo societário localglobal vigente.

\section{Da pandemia ao pós-pandemia: desafios à educação ambiental escolar}

A emergência da COVID-19, provocada pelo novo coronavírus (SARS-CoV-2), acarretou uma série de abalos de ordem econômica, social, política e ambiental em todo o planeta. Milhões de infectados, cidades inteiras em lockdown, milhares de mortos e o aprofundamento, sobretudo nos países em desenvolvimento - sob uma ótica desenvolvimentista capitalista - de problemáticas econômicas, que se projetaram na ampliação do desemprego, no colapso dos sistemas de atenção básica à saúde, crises políticas, dentre outras, como pôde-se constatar nos últimos meses no Brasil, por exemplo.

Como exemplo mais nítido, globalmente falando, de insatisfação com a atual governança exercida frente à pandemia da COVID-19, o Brasil foi um dos países mais afetados pela pandemia e colheu frutos amargos da ausência de preocupação das autoridades ocupantes de altos cargos na capital federal, em Brasília-DF, além de toda a teia de desinformação e propagação de inverdades que acirraram, ainda mais, os ânimos da população, por um lado, mas por outro incitou outra parte da população a um desdém pela situação pandêmica e a um incentivo de medidas médico-farmacêuticas inapropriadas para a contenção do avanço da pandemia (VENTURA et al, 2020).

Se, por um lado, verificamos que no campo da saúde pública houve gargalos enormes, e ainda há, por outro, verifica-se que a educação sofreu amargamente, também, com o despreparo e desorientação das autoridades políticas. Um setor que já é historicamente desgastado e desassistido pela política nacional teve de enfrentar as incertezas produzidas por uma inoperância estrutural e por um rearranjo adaptativo para que professores e alunos conseguissem cumprir o período letivo de 2020. As práticas pedagógicas, agora espacializadas no ciberespaço, tiveram de lidar com os atropelos de um ano atípico, com a saúde mental prejudicada dos trabalhadores da educação, com a ausência de material apropriado para os alunos e com as gambiarras políticas que sustentaram toda essa transição do ensino presencial ao ensino à distância. Tal como argumenta e questiona Souza (2020, p. 111)

No período da pandemia, novas relações afetivas e profissionais foram criadas e ressignificadas, muitas pessoas passaram a trabalhar remotamente; famílias passaram a conviver cotidianamente com vários conflitos; pessoas ficaram afastadas de entes queridos para se proteger e proteger o outro; muitos continuaram nas suas atividades por serem essenciais, por não terem outra opção para se manter ou mesmo por não acreditarem que o vírus é real. Enfim, é uma nova realidade que se apresenta. Mas, e 
a escola? Quais os impactos da pandemia na educação? E os professores e professoras, que, como quaisquer outros cidadãos, passam por todas estas dificuldades, como estão vivenciando esta nova realidade? Quais os impactos e desafios da quarentena para escolas, estudantes e professores? Estas questões nos instigam a continuar pesquisando e vivenciando a educação em tempos de pandemia.

Desse modo, é necessário compreender, em primeiro plano, que a pandemia surgiu como vetor de denúncia para que a população visualizasse os desafios das práticas pedagógicas contemporâneas, que precisam de todo o suporte necessário para acontecer, caso contrário, noutros momentos, estaremos repetindo os mesmos erros e prejudicando futuros anos letivos; em segundo plano, esse período também indicou a necessidade de novas apostas para a educação nacional, sendo uma delas o ensino híbrido - síncrono ou assíncrono - ou à distância, os quais já vinham sendo postos em prática no ensino superior, principalmente, mas agora também precisam adentrar a educação básica; em terceiro plano, a pandemia revelou a fragilidade humana em suas múltiplas dimensionalidades, seja física, mental e interpessoal, ou seja, no campo das relações sociais, uma vez que as limitações impostas pelas circunstâncias distanciaram-nos uns dos outros em nome da vida, da saúde coletiva e do bem estar social.

As regras que impuseram o isolamento social e a operacionalização da educação nesses mesmos termos funcionaram para não apenas inutilizar o espaço escolar físico e lançá-lo na rede, virtualizando-o, mas projetou, nesse espaço, novos desafios criados a partir de desafios anteriores que a educação já lidava há tempos, e criou outros que anunciam, amplamente, que é preciso permanecer atento ao que virá em seguida, quando e se conseguirmos sair com segurança da pandemia (SOUZA, 2020). Educar em tempos de crise é um desafio complexo e que requer uma organização profunda, uma reflexão contínua e, sobretudo, coragem para não repetir as mesmices e enfrentar os desafios que certamente surgirão.

Nesse cenário e diante dessas circunstâncias, a Educação Ambiental, organizada curricularmente, pensada e concebida dentro do espaço escolar, aparece reduzida, esquecida, em virtude da preocupação mais forte em dar conta dos conteúdos centrais da aprendizagem escolar, afastando outras práticas embebidas em eixos temáticos diversos e contemporâneos, que também compõem a organização curricular que estrutura o ensino nacional. Pela falta do espaço físico e pela precariedade do virtual, a Educação Ambiental foi pouco pensada e executada nesse período, mas ela continua existindo e lembrando-nos de sua importância para a confecção de uma consciência socioambiental que possa lidar com os desafios sociais e ambientais que se intensificaram e foram expostos com mais clareza a partir crise pandêmica.

Segundo Jacobi (2015), a Educação Ambiental atua como fomentadora de outras posturas, práticas e consciências que se põem à serviço da transformação do modo de vida, criando outras existências sociais amplamente preocupadas com as questões ambientais. $\mathrm{O}$ viver na cidade e no campo, a qualidade e segurança alimentar, o saneamento básico, a higiene pessoal e coletiva, a qualidade do ar e da água, são problemáticas com as quais a Educação Ambiental tem lidado, desde que instituicionalizada e curricularizada como eixo transversal na educação nacional (LOUREIRO, 2007; NARDY; DEGASPERI, 2016), mas que assumem uma nova roupagem neste período pandêmico e após este. A Educação Ambiental tem uma contribuição fundamental para a formação de sujeitos sociais comprometidos com a qualidade de vida socioambiental num plano coletivo e isto inclui, certamente, as práticas sociais que podem salvar vidas.

Noutros termos, a Educação Ambiental que aqui é exposta atua como propulsora de um modo de existência humana que se compromete com as questões ambientais em vários níveis e graus de complexidade, inclusive no entendimento do quão necessário é adotar outras maneiras que permitam a convivência social e a manutenção da vida do individual ao coletivo. Porém, que seja dito com clareza, que não se trata de um novo apostilamento de boas práticas em Educação Ambiental, tendo a pandemia e o pós-pandemia como pano de fundo, mas a 
construção individual-coletiva de práticas pedagógicas libertadoras e que tecem existências centradas em novos valores e numa ética socioambiental que abraça a vida na Terra como causa a ser levada como compromisso cotidiano. Dentre outros tantos termos e nomenclaturas, aborda-se uma Educação Ambiental crítico-transformadora, como pontua Tozoni-Reis (2008).

Dentre as abordagens educativas que inspiram as práticas pedagógicas formadoras de consciências a partir da Educação Ambiental, a crítico-transformadora é a que mais está alinhada às expectativas e necessidades somadas aos desafios seculares para a educação, de modo mais amplo. A Educação Ambiental crítico-transformadora assume um papel formativo de grande representatividade para os tempos de pandemia e após ela, uma vez que essa perspectiva se apropria de um debate político crítico e transformador, munindo os sujeitos de conhecimentos e valores que os possibilite combater as desigualdades socioambientais marcantes neste século, elevando-os ao protagonismo socioambiental construtor de rotas de saída para as problemáticas que acirram a crise. Noutros termos, a Educação Ambiental críticotransformadora é concebida "como um processo político de apropriação crítica e reflexiva de conhecimentos, atitudes, valores e comportamentos que têm como objetivo a construção de uma sociedade sustentável nas dimensões ambiental e social" (TOZONI-REIS, 2008, p. 157).

Nesse caso, o que acontece é a ressignificação de temas cotidianos e das práticas sociais e políticas, que já se faziam presentes na Educação Ambiental, envolvendo-os em novas necessidades impostas pela pandemia e pelas incertezas produzidas por ela quanto a futuras pandemias, já previstas. Por (re)trabalhar a relação do homem com a natureza, reequilibrando uma relação há décadas desgastada, na qual o homem sempre se sobrepõe, a Educação Ambiental assume, agora, a árdua tarefa de promover uma razão sensível que não esteja mais alicerçada às cartilhas de boas práticas ecológicas e à manutenção de uma ideia desenvolvimentista dita sustentável, mas que continua predando a natureza inconsequentemente e provocando distúrbios, como a pandemia enfrentada.

Para Fraga (2016), essa razão sensível diz respeito a duas questões fortemente presentes e intrínsecas à EA: a racionalização das questões socioambientais, de modo a compreender os interstícios e as nuances, causas e consequências da crise socioambiental, de modo crítico, político, econômico e social; a sensibilidade consciente para lidar com as intempéries provocadas pelos desarranjos entre homem e natureza, de modo que não apenas seja praticada uma sensibilidade vazia de materialidade, mas alicerçada numa razão emocionada e numa emoção racional, transformadora e coletiva, em sua essência. E isto advém de uma relação profunda entre conhecimento e experiência, que não devem esvaziar-se um do outro, pelo contrário, conhecer é uma experiência teórico-prática permanente, portanto teoria e prática devem caminhar lado a lado, nutrindo uma a outra e construindo os sentidos capazes de levar à compreensão dos mais diversos fenômenos que cercam o existir humano. E a Educação Ambiental propicia esses sentidos, essa nova existência, na medida em que trabalha as relações que o homem tem consigo, com o outro e com a natureza, de modo indissociável (GUTIÉRREZ; PRADO, 2013).

À medida em que Educação Ambiental e pandemia se entrelaçam, percebe-se, claramente, o papel fundamental que esse eixo exerce nas práticas pedagógicas contemporâneas: humanizar a natureza e naturalizar a humanidade. Refere-se, portanto, ao fato de que "A aprendizagem como ato dialógico requer a compreensão das mútuas relações entre natureza não humana e o mundo humano" (CARVALHO, 2004, p. 82) e, portanto, a leitura mais cara aos tempos em que vivemos: toda vida é importante e necessária. Se, por um lado, ainda lutamos para reforçar a vida humana e a vida não humana - como as árvores, os animais, a água, o ar etc. - como semelhantes e necessárias ao equilíbrio ecológico planetário; por outro lado, o desafio se assevera diante da pandemia e das incertezas futuras que a seguem, indicando que não é mais suficiente educar para o meio ambiente a partir de propostas interventivas e práticas pedagógicas pontuais e esparsas. A educação, em si, carece de ser toda ela ambiental, 
na medida em que ensine todos nós, sujeitos dela e nela circunscritos, a como construir as alternativas para lidar com os desafios do nosso século, do nosso espaço-mundo, da nossa vida.

Compreende-se então, que o papel da Educação Ambiental na formação escolar vai além de uma movimentação em torno de pontuais práticas pulverizadas no calendário escolar, mas uma intervenção crítico-social que reconecte o sujeito ao seu ambiente e, assim sendo, mostrelhe os caminhos possíveis de serem trilhados para a efetivação das transformações que seu protagonismo socioambiental pode exercer. A escola requer práticas que reforcem os protagonismos, como salienta Arroyo (2013). Esses protagonismos, aqui interceptados pela Educação Ambiental, tornam-se socioambientais, e assim devem ser mantidos, uma vez que, neste século, as implicações das práticas sociais no espaço, quer seja ele humanizado ou natural, acarreta impactos de variadas escalas. Isto é, o sujeito do cotidiano é um sujeito apto a tanto impactar negativamente quanto positivamente, no entanto a formação escolar, fugindo dos apostilamentos e levando os indivíduos em escolarização a uma razão sensível sobre o ambiente em que se inserem, potencializa um protagonismo positivo, comunitariamente enfocado na transformação socioambiental (BOTÊLHO; SANTOS, 2020).

Jacobi (2015), ao mencionar o conhecimento social como resultado da construção dessa Educação Ambiental que alia a consciência dos riscos a uma permanente aprendizagem social, indica que, na atualidade, não há como desvincular a temática em tela de uma visão social, uma vez que os problemas ambientais estão cada vez mais arraigados a vida dos sujeitos, em suas comunidades e em seus cotidianos. É preciso, portanto, elucidar esses indivíduos sobre o que fazem e sobre o que podem fazer, munindo-os de conhecimentos pluralistas que lhes sirvam de mecanismo para uma ação outra, uma ação transformadora do espaço de vida. E a pandemia tem revelado a necessidade disso, de um pensamento comunitário e de uma visão coletiva, no entanto sempre voltando os olhos para si, para os impactos de sua ação individual no plano coletivo e do quanto é necessário mudar em permanência as práticas sociais cotidianas individuais para que elas impactem positivamente esse plano coletivo, como destaca Loureiro (2003).

Isso precisa ser dito com mais atenção. Na verdade, a pandemia tem nos ensinado a como caminhar em meio a um caos generalizado, a como construir um caminho em meio ao caos, o qual pode ser evitado ao mudarmos práticas comuns do cotidiano, tanto em favor da saúde e bem-estar individual quanto coletivo. Como argumentam Ventura et al (2020), trata-se de uma convivência centrada em uma nova ética socioambiental, pautada em valores que estejam alinhados ao equilíbrio entre homem-homem-natureza. Isto é, mover dentro da sociedade a ideia individual-coletiva de que as práticas sociais, por mais comuns que sejam, estão inseridas num coletivo e é preciso ter consciência dos impactos que podem causar.

A Educação Ambiental que se volta aos desafios deste século almeja não somente o trabalho pedagógico e formativo embebido num ambientalismo esvaziado de uma compreensão de sociedade, mas firma-se como eixo capaz de trilhar uma formação socioambiental, como salienta Lobino (2013), que possibilite um redescoberta do cotidiano social como palco para protagonismos outros, enfocados nas possibilidades de mudar e melhorar as condições e meios de vida. Com o cenário pandêmico, e todos os fatores e circunstâncias que nele e a partir dele nos foram revelados, firma-se um novo propósito para a Educação Ambiental como eixo propício a ser tornado capacitador de sujeitos sociais que alteram seu modo de enxergar o mundo e constroem outras práticas socioambientais, que se integrem a valores como a solidariedade, a alteridade, o diálogo, a reflexão-ação e a mudança permanente.

O século XXI já tem dado inúmeros sinais de que é um tempo decisivo para a história humana: ou reinventamos nossa existência e nos conectamos com ideias para além do capitalismo predatório e nocivo à Terra ou teremos de aguardar pelo esgotamento da Terra e a saturação socioambiental, colapsando, sem precedentes, a existência do homem. A pandemia da COVID-19 nos alerta, também, para isso, assim como outras problemáticas atuais que devem 
servir de gatilho para iniciarmos um processo de redescoberta da nossa humanidade e, a partir disso, uma reconexão com a Terra, como pondera Gadotti (2001). A Terra, enquanto lar coletivo, habitada por povos das mais variadas práticas culturais sócio-históricas, nos alerta todos os dias para a necessidade de mudar, de dar um novo sentido ao que estamos fazendo com nossas próprias histórias de vida. É preciso mudar e a escola, a educação, a Educação Ambiental têm muito a contribuir para essa mudança. Os desafios deste século, a agenda global com a qual iniciamos o século XXI, se ampliaram e estão nos alarmando para novas posturas frente a intensificação de problemas já conhecidos e o surgimento de outros, que acontecem sem previsão, como é o caso desta crise pandêmica, por exemplo.

Os desafios impostos à Educação Ambiental são múltiplos, a partir dos pontos destacados. A pandemia revela a necessidade de reconfigurar e reinventar as práticas sociais, de modo a promover outra convivência ambiental entre os homens e a natureza. O póspandemia trará à escola novas pautas e práticas, sobretudo em face dos problemas que foram escancarados neste período pandêmico? $\mathrm{O}$ que restará às práticas pedagógicas em Educação Ambiental, tanto frente aos desafios socioambientais locais-globais acarretados pela pandemia quanto pelos desafios que aportam à educação? As respostas a essas questões podem estar longínquas, no entanto é preciso fazer novas apostas crítico-transformadoras, tecendo ideias que podem oxigenar a Educação Ambiental e construir novos caminhos e alternativas que propiciem outros roteiros, práticas e saberes-fazeres. Nesse sentido, apresenta-se o Bem Viver como aposta, como ideia e como novo caminho para se pensar-agir em Educação Ambiental.

Por não haver certeza e clareza alguma do que virá em seguida, após a superação da pandemia, é difícil trazer respostas aos questionamentos anteriores e a outros que, porventura, surjam nos próximos passos dados. Entretanto, não se pode transformar a imprevisibilidade e a incerteza produzidas pela pandemia em freio para propor possibilidades que tornem e transformem a Educação Ambiental em um mecanismo crítico-transformador gerador de protagonismos socioambientais que estes tempos urgem. Nesse caso, o Bem Viver, apostado por Acosta (2016) como veículo transformador da sociedade global atual, move-se a partir da redescoberta da vida e da humanidade, insurgindo-se nesse cenário a partir de tessituras críticas e reflexivas, pedagogicamente situadas e em diálogo com a Educação Ambiental, afirmando que ainda é possível mudar, que ainda é possível trilhar outro caminho e ecoconviver uns com os outros e com o planeta. E não se trata de uma tentativa de driblar crises futuras que estão arraigadas à crise macroestruturante local-global, mas, sim, de construir uma consciência individual-coletiva que mobiliza ações transformadoras neste mundo, nesta Terra-pátria, em busca de um viver melhor, do Bem Viver.

\section{Bem Viver: ideia(s) e esperança(s)}

O Bem Viver é um compilado teórico-metodológico-experiencial, trazido não apenas como um eixo fomentador de debates acerca da vida, da relação sociedade-natureza e das transformações societárias contemporâneas no âmbito acadêmico. É um debate multirreferencializado, permeado por muitas outras ideias e utopias críticas, as quais atravessam o tempo e as gerações, os povos e culturas, para expressar e ressignificar o desejo por uma reinserção do homem como sujeito criativo e não destrutivo, sujeito reflexivo e não desmedido e inconsequente, sujeito harmônico e não provocador de rupturas negativas. Mas é preciso salientar, também, que o Bem Viver se constitui, primariamente, como uma contracorrente ao desenvolvimentismo capitalista, insurgindo-se como resposta contemporânea à necessidade do combate às desigualdades que fundamentam a sociedade-mundo global. Como salientado por Acosta (2016, p. 32) 


\begin{abstract}
O Bem Viver - isto é fundamental - supera o tradicional conceito de desenvolvimento e seus múltiplos sinônimos, introduzindo uma visão muito mais diversificada e, certamente, complexa. Por isso mesmo, as discussões sobre o Bem Viver, termo em construção, são extremamente enriquecedoras. O Bem Viver revela os erros e as limitações das diversas teorias do chamado desenvolvimento. Critica a própria ideia de desenvolvimento, transformada em uma enteléquia que rege a vida de grande parte da Humanidade - que, perversamente, jamais conseguirá alcançá-lo.
\end{abstract}

Significando, assim, que o Bem Viver é uma aposta crítico-transformadora em construção, que indica a necessidade de viver de outra forma, fora de modelos já notadamente falidos e que não têm proporcionado, de modo igualitário, o acesso da população ao mínimo necessário para a qualidade de vida coletiva. Ressalta-se, mais uma vez, a educação como caminho através do qual é possível, também, construir noções sobre e para o Bem Viver. Uma vez entendendo-o como um devir, uma teoria e experiência em movimento de vir a ser, a educação propicia o entendimento da vida e das múltiplas jornadas trilhadas por ela, em sociedade, sejam passadas ou presentes e futuras, que podem corroborar a ideia do Bem Viver como aposta para este milênio, ou melhor, para as próximas décadas, que serão decisivas para a humanidade.

A pandemia do novo coronavírus nos levou ao entendimento do quão frágil é a sociedade global e o viver nela. Estamos presos em ciclos viciosos, repetitivos e (im)produtivos, mergulhados em nosso caos cotidiano rotineiro e exaustivo, sempre circulando de um lado para outro dos espaços sociais coletivos e, quando é chegado o risco, tudo isso é alterado subitamente. Mas não podemos desvincular tal pandemia do cenário de crise global que tem se intensificado, nos últimos anos, e que tem nos mostrado a necessidade iminente de rever o que chamamos de desenvolvimento e de vida dentro dessa ideia puramente desigual. Para construir as alternativas e a fuga da intensificação desses acirramentos desiguais na sociedade-mundo, o Bem Viver se trata da efetivação de um modelo societário que corresponda às expectativas e esteja calcado nas experiências de todos os povos, que carregam consigo formas outras de compreender-atuar no mundo e que poderão impactar positivamente nos efeitos de crises que virão, sem dúvida, em seguida a esta que vivemos hoje.

\footnotetext{
As pessoas devem organizar-se para recuperar e assumir o controle das próprias vidas. Contudo, já não se trata somente de defender a força de trabalho e de recuperar o tempo livre para os trabalhadores - ou seja, não se trata apenas de opor-se à exploração da mão de obra. Também está em jogo a defesa da vida contra esquemas antropocêntricos de organização produtiva, causadores da destruição do planeta (ACOSTA, 2016, p. 35)
}

A construção de um outro olhar para a vida, para a humanidade e para a sociedademundo contemporânea precisa perpassar pela ideia de que, na mesma medida em que precisamos produzir, também precisamos exercitar a solidariedade, a consciência socioambiental, o diálogo, a alteridade e outras características humanitárias perdidas no antropocentrismo capitalista e desenvolvimentista dos dias contemporâneos. A vida pede socorro. Mas, é pertinente dizer que o Bem Viver não surge como uma cartilha pronta para atender ao pedido de socorro da Terra e da vida, ele surge como ideia libertadora (SEZYSHTA, 2018). É preciso abrir os caminhos para se pensar diferente, fora das ideias castradoras que ainda amarram as consciências dos sujeitos sociais, impedindo que enxerguem e pensem de doutra maneira.

O Bem Viver é uma tomada de consciência. Consciência horizontal, coletiva, solidária e socioambiental. Dito isso, convém alinhavar as três dimensões que estão articuladas à propositura: a ideia, a aposta crítico-transformadora e a esperança. Ao designar o Bem Viver como possibilidade para viver uma outra sociedade global, refeita a partir de outro olhar sobre 
si mesma e sobre o futuro que esta se deseja, Acosta (2016) indica que tal possibilidade vinculase a uma nuvem de ideias, sendo ela mesma uma ideia proveniente das vivências e experiências de múltiplos povos tradicionais e originários que já apregoavam a harmonia Terra-homem como algo indiscutível e importante para permanência estável da vida. Povos, estes, que em sua maioria, concentra-se abaixo da linha do Equador, no sul planetário, esquecidos historicamente pelo desenvolvimento global concentrado nos países do norte, as chamadas potências globais.

Mas há, também, outras filosofias que tecem outras argumentações e ideias para o Bem Viver e que provém de comunidades esquecidas, também, dentro desses países centrais e centralizadores. Ou seja, é um movimento histórico, de muitas culturas praticadas por povos em vários lugares do mundo, de concentração de ideias que incitam uma nova ordem mundial pautada em quatro princípios-chave, que são "reciprocidade, relacionalidade, complementariedade e solidariedade entre indivíduos e comunidades" (ACOSTA, 2016, p. 41). Esses princípios compõem os pilares do Bem Viver como estrutura possível de ser implementada, até mesmo, no regimento legal de um país, como é o caso do Equador, que reconhece constitucionalmente tal ideia. E mesmo concentrado em povos de origem amazônica e andina, como maiores expoentes contribuintes para essa ideia, ainda há a possibilidade de pensá-la, igualmente, em comunidades convencidas de suas formas capitalistas de viver.

Em outras palavras, a discussão sobre o Bem Viver não deveria circunscrever-se às realidades andina e amazônica. Apesar de conhecermos a extrema dificuldade para se construir o Bem Viver em comunidades imersas no turbilhão do capitalismo, estamos convencidos de que há muitas opções para começar a praticá-lo em outros lugares do planeta, inclusive nos países industrializados (ACOSTA, 2016, p. 46-47).

O ideário do Bem Viver nos diz muito sobre a aposta crítico-transformadora, urgente para este século. No início dos anos 2000, quando o mundo se deparava com um novo século pela frente e, com ele, inúmeros desafios e incertezas globais a superar, sobretudo no campo dos avanços e arranjos sociotécnicos e econômicos que viabilizariam a chamada Nova Ordem Mundial, cada passo dado em uma nova direção, para construção do mundo como hoje o conhecemos - após mais de vinte anos do início deste século - era uma conquista do capitalismo. Em contrapartida, o quanto nos foi cobrado, até aqui, por todo avanço também ficou claríssimo nos últimos vinte anos. A destruição da natureza, como máxima expressão visível de todo esse avanço atrelada à perda da qualidade de vida global e às crises socioambientais em cada nação - que se atrela a uma crise historicamente macroestruturada revelam que o mundo mudou, sim, que estamos vivendo sob uma nova ordem, mas cujo custo é altíssimo e poderá nos levar a um colapso sem precedentes na história. A pandemia é uma das faces, até então, mais asseveradas desse processo, prejudicando, intensamente, o ritmo desenvolvimentista até aqui praticado ao máximo, como máxima capitalista.

Trata-se de uma reversão, ao inverter os valores deste século. Ou seja, significa romper com tudo o que nos cobra, desarmonicamente, a vida como preço a ser pago pelo avanço sociotécnico-econômico contemporâneo para reivindicar à humanidade sua humanidade, os direitos do homem e da natureza, quebrando o julgo do subdesenvolvimento e das desigualdades sociais e ambientais globais, dos preconceitos múltiplos, das violências, da escassez e do apagamento histórico sofrido por inúmeros povos (ACOSTA, 2016; ALCÂNTARA; SAMPAIO, 2017). No plano político, como aposta crítico-transformadora, trata-se de romper com uma política embebida no economicismo neoliberalista, que apenas volta suas atenções à manutenção do setor privado e da expansão de mercados mundo afora, na tentativa de se lançar no jogo igualmente desigual entre as nações.

Trata-se de uma política não dominante, em que o papel do Estado não seja hierarquizado por uma complexa teia de sujeitos que pouco se comunicam com as reais necessidades das pessoas, mas uma política horizontal, voltada aos interesses de todos os 
cidadãos de um país, que igualmente necessitam sentir-se acolhidos, respeitados e cuidados por sua terra. $\mathrm{O}$ desencantamento com o desenvolvimento é uma necessidade para essa política. Antes eufórica com tal ideia de conquistar o ápice econômico-social, agora necessita rever-se como caminho para a mudança e para um não negacionismo do direito à vida das pessoas e à vida da natureza.

Trata-se de uma aposta crítico-transformadora que, no campo político, é vislumbrada com estratégia possível e ideia plausível para repensar algumas noções, como a de cidadania e o papel do Estado em proporcioná-la, mirando a contemporaneidade e as urgências que demandam tais ressignificações. É uma nova política feita para e pelas pessoas, pelos povos, pelas ideias que costuram um futuro melhor e que buscam efetivá-lo como direito igual de todos, pautado na justiça social e ambiental, como argumenta Acosta (2016). Sezyshta (2018) pondera, de modo semelhante, e corrobora com tal raciocínio, ao argumentar em favor de um discernimento do mundo que, em mesma medida, discerne a necessidade de implementar alternativas sociais e políticas que encaminhem a mudança e o ecoconviver como pautas fundamentais para este século.

Trata-se de um desenvolvimento centrado em aportes qualitativos, não mais quantitativos, uma vez que o capitalismo desenvolvimentista não se preocupa em gerar bens e serviços atrelados às necessidades humanas, mas na obtenção do lucro associado à geração de novas necessidades que criam hiatos entre o que realmente é necessário e o que não é. Em resumo, Sezyshta (2018, p. 93) assim afirma:

\begin{abstract}
O enfrentamento ao sistema opressor, que segue gerando novas vítimas, se dá pelo esforço coletivo de prática da verdade e de defesa da vida, nas identidades compartilhadas, na tolerância multiétnica enquanto contribuição latino-americana para a história mundial. Essa já é uma transmodernidade, uma novidade diante do mundo, já em gestação, anúncio da possibilidade real de um desenvolvimento qualitativo, capaz de efetivamente priorizar a vida humana diante do lucro, afinal, um bilhão de pessoas ainda passa fome no planeta, em pleno século XXI.
\end{abstract}

Portanto, o Bem Viver afirma a necessidade de revisitar as práticas sociais e políticas atuais, buscando, através desse movimento crítico-transformador, uma nova roupagem para estas e, de tal forma, que seja possível caminhar para a construção individual-coletiva de outra sociedade horizontalizada e harmônica em muitos aspectos. Essa é a maior esperança que emana do Bem Viver. O desenvolvimento capitalista já mostrou que dentro dele não há saída, que suas engrenagens ora funcionam muito bem ora param e, com isso, os efeitos são severos, salvando-se apenas aqueles que obtiveram maior lucro durante o seu funcionamento, ou seja, uma elite que concentra riquezas às custas das desigualdades geradas pelo desenvolvimento.

$\mathrm{O}$ Bem Viver assume uma postura esperançosa, mesmo diante do cenário atual de crise pandêmica, uma vez que a ideia crítico-transformadora não esmorece frente aos desafios que se interpõem à sua existência e que, muitas vezes, tentam tirá-lo de cena para que não se faça notório entre as pessoas (ACOSTA, 2016). Os movimentos sociais contemporâneos são a maior expressão de luta social contra a hegemonia do capital neoliberal, como frisa Soffiati (2008), e muitos deles têm reconhecido o Bem Viver como caminho para repensar os roteiros sociopolíticos atuais, na tentativa de conceber outros avivados pela esperança de um viver bem. A economia solidária, por exemplo, tem sido um caminho assumido para estabelecer uma contracorrente econômica às práticas empresariais nucleadas pela ideia do neoliberalismo mercantil, baseado na disputa desigual de mercado e na predação econômica dos consumidores, como destaca Sezyshta (2018).

A solidariedade é uma das maiores máximas do Bem Viver. Esta tem se perdido, no emaranhado global de práticas sociais que se individualizam com o passar dos tempos, retirando toda a ideia do coletivismo social e da convivência harmônica entre as pessoas. Nos últimos 
meses, a solidariedade se mostrou essencial para a manutenção da vida, assim como outros pilares do Bem Viver, já destacados. Colocar-se no lugar do outro, entender seu papel e função social no combate à disseminação do vírus, promover o respeito à vida se tornaram fundamentais para a convivência com a pandemia e para sua superação. No entanto, a sobreposição da economia, que foi abalada sob o efeito da crise pandêmica atual, provoca uma reflexão profunda sobre o quanto a vida está agrilhoada ao economicismo, não importando tanto aos poderes políticos, que projetam ideias deturpadas no plano social, os custos disso em curto prazo. É preciso repensar o valor da vida e o quanto a vida não tem valor financeiro.

Por fim, é preciso revelar que não há uma conceituação, uma definição cartesiana, para o Bem Viver. Basta que o entendamos tal qual a própria expressão já revela por si mesma: é o viver bem, o Bem Viver. Nos mais variados campos que transitam pela vida, o Bem Viver encontra uma forma de reconfigurar e ressignificar a maneira como concebemos e nos comportamos, como sociedade, dentro dessas trajetórias. Dentre elas, destaca-se a trajetória educativa. Como salienta Gadotti (2001), a Terra tem urgência de novas ideias que possam corromper velhas ideias e práticas. A educação, sobretudo a Educação Ambiental, apresenta-se como vereda por onde percorrem essas ideias avivadas pelo desejo de um amanhã, de um porvir a partir do que é feito hoje. Pensar globalmente e agir localmente nunca foi tão imperativo, e é por isso que o Bem Viver se faz tão necessário dentro dos percursos educativos, frisando que a vida que levamos hoje pode e deve ser outra, na busca pela qualidade em todos os campos sobre os quais a vida se assenta.

\section{Bem Viver e Educação Ambiental: apontamentos e proposituras crítico- transformadoras}

Os enfrentamentos aos cenários desenhados pela crise pandêmica contemporânea perpassam pelas salas de aula. Isolados uns dos outros, alunos e professores viram-se imersos noutros espaços pedagógicos de aula, erguidos pelas tecnologias e não mais pelas paredes do espaço físico. Então, pensando nisso, como colocar em diálogo o Bem Viver e a Educação Ambiental, de modo a tecer práticas formativas escolares que naveguem noutra direção e atinjam outras consciências? É um desafio complexo, que exige de ambos os lados o entendimento de que a Educação Ambiental independe do espaço físico e carece de impregnar a vida cotidiana dos que a fazem.

Educar socioambientalmente vai além das pormenorizações educativas que pulverizam o calendário escolar, às vezes retendo esse eixo temático a datas comemorativas, sem gerar um real conhecimento sobre e para o mundo dos sujeitos alcançados por essas práticas. $\mathrm{O}$ desenraizamento de práticas em uma Educação Ambiental castradora de consciências perpassa pela noção de que o sujeito está diariamente vivendo em um ambiente e este mesmo necessita da reflexão-ação contínua desses indivíduos. Padilha et al (2011), assim como Loureiro (2003), destacam e afirmam que o meio ambiente é todo o ambiente palco da ação social, cidadã em sua essência, do indivíduo e da coletividade, portanto é preciso um entendimento, uma leitura interpretativa dos fatos, transitando a uma compreensão e posterior ação transformadora que coopere com a mudança ambicionada pela Educação Ambiental.

A pandemia é um cenário contemporâneo que demonstra a necessidade dessa razão sensível, como sinaliza Fraga (2016), para atuar no combate à propagação do vírus, mas, também, na garantia da qualidade de vida coletiva e no viver bem de todos. A ideia do ambiente vivido cotidianamente como palco da ação do sujeito possibilita o protagonismo socioambiental, entendendo este como caminho através do qual os sujeitos se municiam de uma permanente ação-reflexão que não esteja apegada a uma visão encartilhada de prescrições ambientais, mas ao entendimento do quanto esses sujeitos podem atuar para a manutenção da 
qualidade de vida nos espaços coletivos cotidianos, como a rua, o bairro, a cidade e daí para escalas maiores.

De certo modo, mesmo compreendendo a necessidade de pensar também no isolamento social como oportunidade para potencializar esse protagonismo socioambiental, também se pensa nos desafios trilhados pelos sujeitos do ensino-aprendizagem escolar, que se defrontam com os múltiplos impedimentos para a efetividade desse trabalho. E, então, chegamos ao ápice para uma nova questão: seria inviável percorrer práticas educativas socioambientais, dentro da perspectiva do Bem Viver, tendo em vista o contexto educativo virtual atual? Realmente, tornase complicado pensar em como estimular uma inserção socioambiental dos sujeitos em formação, perpassando por um exercício protagonista a partir de suas comunidades, diante do isolamento provocado pela pandemia e da virtualidade, que traz consigo dificuldades quanto à veiculação de propostas que levem os sujeitos ao protagonismo cotidiano.

É na escola que se tornam muito mais efetivas tais práticas formativas. A escola é um lugar privilegiado para a ocorrência de práticas que tragam consigo essas novas ideias, tal qual é o Bem Viver. Não que a escola virtualizada não o seja, mas ela é muito mais limitada, sobretudo pelos percalços encontrados: alunos que não dispõem de equipamentos, professores altamente atarefados e angustiados, a ausência do contato e da proximidade, a carência do espaço físico-afetivo que estimula relações de aprendizagem mais aprofundadas etc. Educar, dentro desse cenário, é um redemoinho complexo de angústias, desafios e potencialidades, visto que, ao mirar esta última, há inúmeras ferramentas que cooperam e estimulam aprendizagens personalizadas e multidirecionais, estimulando o colaborativismo pedagógico a partir de metodologias que reativam o ensino-aprendizagem por meio das tecnologias e mídia digitais, como ressalta Morán (2015).

Assim, surge um novo questionamento: como estimular a solidariedade, a alteridade, a convivência horizontal e outros elementos essenciais e uma nova postura frente aos desafios contemporâneos dentro da teia virtual que tenta assumir-se como sala de aula? É um desafio gigantesco. A ausência da proximidade, do contato, do diálogo, levando em consideração que o ser humano se constitui, essencialmente, pelas interações sociais cotidianas, torna muito mais nebuloso pensar em alternativas que cooperem para a inserção da Educação Ambiental e do Bem Viver como trajetórias a mudarem a relação dos sujeitos com e no mundo. O que se quer dizer com isso é que a Educação Ambiental necessita da vivência cotidiana, da experiência com os lugares e com as pessoas, o que é inviável em virtude do isolamento social provocado pela pandemia. O perigo reside em cair na teorização ambiental, na coisificação do meio ambiente, a partir de um conteudismo não provocador de aprendizagens transformadoras, as quais estão intimamente ligadas às experiências cotidianas como elemento crucial para provocações que estimulem os indivíduos a se enxergarem e a enxergar com outros olhos o lugar onde vivem.

Como salientado por Loureiro (2003) e por Jacobi (2015), a Educação Ambiental demanda de uma aprendizagem com e no cotidiano, nas práticas sociais percorridas pelos sujeitos em aprendizagem, e os conhecimentos que estes desenvolvem e constroem na escola precisam comunicar-se com essas vivências. Isolados, em casa, como terão tais experiências? E é aí que precisam ser buscados novos horizontes para a Educação Ambiental, roteirizando-a dentro dos espaços virtuais que tem proporcionado a continuidade da escolarização, mesmo com todas as falhas e percalços detectados. Abre-se um novo horizonte a desbravar para a Educação Ambiental. No entanto, a ideia do Bem Viver mantém-se viva o suficiente para estimular a Educação Ambiental a não desistir de apostar na transformação dos sujeitos sociais mesmo na ausência da presença coletiva, pelo contrário, é possível exercer essa ideia e esperança transformadora dentro dos espaços virtuais de aprendizagem e fora dele, noutros espaços que constroem as redes interconectadas do mundo virtual.

Tudo o que a sociedade-mundo enfrentou até agora deixa explícito o quão importante é mudar. Mudar as atitudes, mudar o olhar, mudar a consciência. Mudar para harmonizar a vida 
com ideias que a elevem e não a privem. A pandemia ocasionou oportunidades de aprendizagem, atuais e posteriores, que nos levam ao entendimento de que é preciso viver por um mundo melhor, mais justo, mais equitativo e menos individualista, menos adoecido e adoecedor, mais acolhedor e afetuoso. O Bem Viver, nisso, inspira as práticas pedagógicas em Educação Ambiental, dentro ou fora dos espaços virtuais de aprendizagem e também na esperança da retomada dos encontros presenciais dentro das escolas. É necessário que a Educação Ambiental não seja apenas uma cartilha de boas maneiras, um conjunto de argumentos unilaterais para mudança das práticas sociais, mas uma aposta críticotransformadora que municia os sujeitos de uma consciência e protagonismo socioambiental, reconectando-os com o lugar de vida, com as experiências sociais cotidianas e, assim, buscando a real mudança (GADOTTI, 2001; PADILHA et al, 2011; ACOSTA, 2016).

Dentro do contexto atual, conectados pela virtualidade, professores e alunos precisam continuar exercitando sua percepção e sua inserção na sociedade-mundo. A Educação Ambiental também está no quintal, dentro de casa, na vida cotidiana que nos cerca e é preciso o desenvolvimento da perícia e da consciência que se volta à problematização, aproximação crítica e o despertar da mudança de dentro para fora, de casa para a rua, da rua para o bairro, do bairro para a cidade, e desta para outras direções e escalas. A reinserção e reconexão do sujeito com seu lugar de vida e com as experiências que perfazem a vida nesse lugar não necessariamente dependem do espaço físico escolar para acontecer, afinal o manuseio de certas ferramentas, assim como a ampliação do (re)conhecimento do mundo a partir da teia de informações, dentro desta sociedade em rede (MORÁN, 2015), proporcionam aprendizagens que transpõem as fronteiras e os impedimentos do estar lá.

Nesse sentido, o Bem Viver abre uma janela para a Educação Ambiental dentro desse cenário, uma janela para ver o mundo a partir de uma indignação e de uma inconformidade com o que tem acontecido e tem retirado da humanidade a qualidade de vida. Da janela da casa, é possível ver as problemáticas que nos cercam, que afetam negativamente a vida e o equilíbrio socioambiental do qual a primeira depende. E, assim, cria-se uma estratégia para desenvolver a Educação Ambiental nestes tempos de crise: reconectar o sujeito com seu lugar de vida, abrindo uma janela para enxergar com outros olhos o mundo em que vive. Significa o despertar de um processo contínuo que demanda um permanente diálogo sobre as razões, causas e consequências passadas e presentes, com projeção futura, sobre o que chamamos de humanidade e de Terra e como nós, enquanto sociedade, dentro de nossos espaços comunitários e de nossas práticas cotidianas podemos atuar em favor do atendimento do pedido de socorro do planeta.

A Educação Ambiental praticada neste momento de isolamento social, inviabilizando ações didático-pedagógicas de caráter intervencionista, é aquela que municia o sujeito do entendimento da situação, não apenas a partir do uso panfletário da informação, mas de um protagonismo informacional que advém da crítica, da reflexão, de um olhar inconformado e indignado com a situação local-global que tem se agravado ao longo das últimas décadas. É estimular um processo de contato com a informação, de modo não panfletário e passivo, mas atuante, politizado e comprometido com a mudança, sobretudo pelo fato de estes tempos requisitarem, ainda mais, uma mudança coletiva de atitude permeada por um contato crítico contínuo com a informação.

É difícil pensar em estratégias didático-pedagógicas que consigam levar em consideração o trabalho remoto dos professores e alunos, sobretudo pelas disparidades socioeconômicas, pela estafa mental e emocional, dentro outros fatores, que incidem diretamente sobre esses sujeitos escolares, nestes tempos (SOUZA, 2020). Se, no formato presencial, já há percalços a serem driblados cotidianamente por esses sujeitos, no formato de educação on-line há outros novos e ainda desconhecidos; para a Educação Ambiental é um terreno ainda pouquíssimo explorado, para não dizer inexplorado. Mas há de se converter os 
desafios em novas propostas, entendendo, sobretudo, que o contexto pandêmico atual nos leva a pensar sobre a nossa existência e o quanto é necessário converter todo pensar individualista em um pensar coletivo, pensar a sociedade como um todo e no quanto o eu social pode contribuir para a efetividade de práticas sociais solidárias, empáticas, altruístas e que se alinhem a uma convivência harmônica com o planeta.

Esse entendimento de mundo perpassa por práticas escolares que reforçam outras miradas, outros giros, fugindo de uma Educação Ambiental praticada apenas como uma fuga do conteudismo de sala de aula. Noutros termos, significa buscar a Educação Ambiental como caminho crítico-transformador que leva os sujeitos a caminhar em direção a outras respostas inovadoras para lidar com os desafios planetários contemporâneos, que não são só políticos ou econômicos, são sociais, são cotidianos e também são meus. E é a partir disso que são feitas novas apostas, pautadas na construção de outros aportes que apontam em uma direção oposta, numa contracorrente ao apagamento da Educação Ambiental ou em sua redução como temática esgotada e obsoleta. O Bem Viver, enquanto perspectiva filosófica, sociológica, geográfica, histórica, mas, sobretudo, experiencial e de vida, aborda com clareza elementos que precisam permear a formação escolar contemporânea, levando os sujeitos escolares a outro olhar sobre si, sobre o outro e sobre o mundo. Um olhar, e práticas, críticas e transformadoras.

Como discutem Padilha et al (2011), aí se cria o espaço para fortalecer uma cidadania planetária, uma noção da Terra como pátria comum, desde os espaços mais próximos de vida até as escalas mais amplas, regando esse percurso por uma incursão dentro da ideia do Bem Viver, a qual se propõe a roteirizar aportes didático-pedagógicos em Educação Ambiental de modo horizontal, dialógico e que entra como caminho para e que se comunica permanentemente com os desafios que são meus, seus e nossos (SEZYCHTA, 2018). Trata-se de construir um caminho de aprendizagem, virtual ou presencial, que lide com as informações que as experiências cotidianas, virtuais ou presenciais, trazem consigo e, partindo daí, problematizar e tematizar a vida de maneira que seja possível ir mais a fundo na compreensão de como acontecem os fatos que cercam os sujeitos em formação, e como eles podem agir de modo crítico-transformador perante esses fatos.

\section{Considerações Finais}

O desafio maior a ser desbravado, na contemporaneidade, é a superação de velhos e falidos artifícios que sustentam uma prática pedagógica obsoleta em Educação Ambiental, abrindo trilhas para mobilizar a construção de outros roteiros, avivados por outras ideias e utopias crítico-transformadoras, como é o Bem Viver.

Não é apresentada uma fórmula, uma prática pronta e replicável, mas uma perspectiva a colaborar com o pensar-agir em Educação Ambiental, sobretudo a partir do cenário de crise pandêmica atual e nos desafios a lidar, tanto nele estando quanto no porvir. É relevante propor miradas contemporâneas que listem um conjunto de ideias que inspiram práticas pedagógicas escolares que mudam a vida dos sujeitos, reconectando-os com sua humanidade e com seus cotidianos, de modo crítico-transformador.

O Bem Viver emerge dentro desse cenário, para provocar não somente um pensar para além dos desafios, vislumbrando as possibilidades e as proposições para lidar com os percalços passados-presentes-futuros, mas entra em cena para nos mostrar que a educação é um caminho de transformação crítica, de mudança humanitária, recuperando valores e ideias que consomem conjecturas que denigrem e furtam o direito de viver bem, de viver melhor. É um agir para além das lógicas que sustém uma educação fragilizada e pouco potencializadora de outras subjetividades transformadas, ativas e conectadas com as reais necessidades do mundo.

Em resumo, reitera-se que não se trata de criar um apostilamento de boas maneiras e bons costumes socioambientais, que respondam aos desafios que existem na experiência 
subjetiva de cada um, mas conduzi-los por um caminho crítico-transformador em que os sujeitos não se tornem apenas sensíveis aos problemas que permeiam suas vidas, mas que haja uma inconformidade e um protagonismo sendo gerado dentro de um movimento, presencial ou virtual, que é socioambiental, comunitário, vivido e, portanto, potentemente esclarecer sobre as necessidades do mundo hoje.

A pandemia nos alerta sobre isso e abre um conjunto de discussões cabíveis para a Educação Ambiental que, agora, vê-se desafiada a adentrar nos circuitos formativos escolares virtuais para continua movendo esses sujeitos do ensino-aprendizagem a buscar a mudança de suas práticas sociais. Metodologicamente, trata-se de estimular diálogos, trocas de experiências, a busca pela informação e sua leitura crítica, o posicionamento social-político-ambiental como estratégias para não fazer definhar a Educação Ambiental, mas maturá-la e elevá-la à condição de trajetória formativa comprometida com o Bem Viver para o hoje e para o amanhã.

\section{Referências}

ACOSTA, A. O bem viver: uma oportunidade para imaginar outros mundos. São Paulo: Autonomia Literária, Elefante, 2016.

ALCÂNTARA, L.C.S.; SAMPAIO, C. A. C. Bem Viver como paradigma de desenvolvimento: utopia ou alternativa possível? Desenvolvimento e Meio Ambiente, Curitiba, v. 40, [s.n.], p. 231-251, abr. 2017.

ARROYO, M. G. Currículo, território em disputa. 5. ed. Petrópolis: Vozes, 2013.

BOTÊLHO, L. A. V.; SANTOS, F. K. S. dos. Ecoformação e protagonismo socioambiental: diálogos e possibilidades ecoeducativas contemporâneas. Revista Brasileira do Ensino Médio, Ipojuca, n. 3, p. 63-75, 2020.

CARVALHO, I. C. M. Educação Ambiental: a formação do sujeito ético. São Paulo: Cortez, 2004.

FRAGA, L. A. de. Educação Ambiental e valores: recriando espaço para uma razão sensível. In: BONOTTO, D. M. B.; CARVALHO, M. B. S. da S (Orgs.). Educação ambiental e valores na escola. São Paulo: Cultura Acadêmica, 2016. p. 139-154.

GADOTTI, M. Pedagogia da Terra: Ecopedagogia e educação sustentável. In: TORRES, C. (Org.). Paulo Freire y la agenda de la educación latino-americana en el siglo XXI. Buenos Aires: CLACSO, 2001. p. 81-132.

GUTIÉRREZ, F.; PRADO, C. Ecopedagogia e cidadania planetária. 3 ed. São Paulo: Cortez, 2013.

JACOBI, P. H. Meio Ambiente, riscos e aprendizagem social. Cadernos de Pesquisa: Pensamento Educacional, Curitiba, v. 10, n. 26, p. 346-364, set./dez. 2015.

LEFF, E. Complexidade, Racionalidade ambiental e Diálogo de saberes. Educação e Realidade, Porto Alegre, v. 34, n.3, p. 17-24, set./dez. 2009.

LOBINO, M. G. F. A práxis ambiental educativa: diálogo entre diferentes saberes. 2 ed. Vitória: EDUFES, 2013.

LOUREIRO, C. F. B. (Org). Cidadania e meio ambiente. Salvador: Centro de Recursos Ambientais, 2003. 
LOUREIRO, C. F. B. Educação Ambiental crítica: contribuições e desafios. In: MELLO, S. S.; TRABJER, R. (Coords.). Vamos Cuidar do Brasil: conceitos e práticas em Educação Ambiental nas escolas. Brasília: Ministério da Educação, Ministério do Meio Ambiente, UNESCO, 2007. p. 65-72.

MORÁN, J. Mudando a educação com metodologias ativas. In: SOUZA, C. A.; MORALES, O. E. T. (Orgs). Convergências Midiáticas, Educação e Cidadania: aproximações jovens. Universidade Estadual de Ponta Grossa. PG: Foca Foto-PROEX/UEPG, 2015. p. 15-33. (Coleção Mídias Contemporâneas Vol. II).

NARDY, M.; DEGASPERI, T. C. Educação Ambiental e cidadania: desafios para a construção do pensamento glocal. In: BONOTTO, D. M. B.; CARVALHO, M. B. S. da S (Orgs.). Educação ambiental e valores na escola. São Paulo: Cultura Acadêmica, 2016. p. 119-137.

PADILHA, P. R. et al. Educação para a Cidadania Planetária: currículo interdisciplinar em Osasco. São Paulo: Instituto Paulo Freire, 2011.

REIGOTA, M. Meio ambiente e representação social. 8 ed. São Paulo: Cortez, 2010.

SANTOS, B. S. Renovar a teoria crítica e reinventar a emancipação social. Tradução Mouzar Benedito. São Paulo: Boitempo, 2007.

SEZYSHTA, A. J. O Bem Viver e outros mundos possíveis. Argumentos, Fortaleza, Ano 10, [s.v.], n. 19, p. 87-93, jan./jun. 2018.

SOFFIATI, A. Fundamentos filosóficos e históricos para o exercício da ecocidadania e da ecoeducação. In: LOUREIRO, F. B.; LAYARARGUES, P. P.; CASTRO, R. S. de (Orgs.). Educação ambiental: repensando o espaço do cidadão. 4 ed. São Paulo: Cortez, 2008. p. 23- 68.

SOUZA, E. P. Educação em tempos de pandemia: desafios e possibilidades. Caderno de Ciências Sociais Aplicadas, Vitória da Conquista, v. 17, n. 30, p. 110-118, jul./dez. 2020.

TOZONI-REIS, M. F. C. Pesquisa-ação em Educação Ambiental. Pesquisa em Educação Ambiental, Rio Claro, v. 3, n. 1, p. 155-169, 2008.

VENTURA, D. F. L. et al. Desafios da pandemia de COVID-19: por uma agenda brasileira de pesquisa em saúde global e sustentabilidade. Cadernos de Saúde Pública, Rio de Janeiro, v. 36, n. 4, p. $1-5,2020$. 